\title{
PRÁTICAS DE CONTABILIDADE GERENCIAL ADOTADAS POR SUBSIDIÁRIA BRASILEIRA DE INDUSTRIA ALEMÃ DE GRANDE PORTE
}

\section{MANAGEMENT ACCOUNTING PRACTICES ADOPTED BY BRAZILIAN SUBSIDIARY OF LARGE GERMAN INDUSTRY}

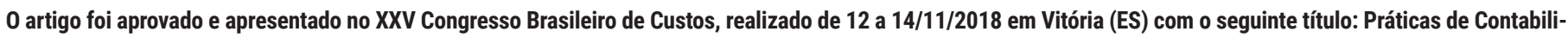
dade Gerencial Adotadas por Empresa Industrial Gaúcha de Grande Porte.

\section{RESUMO}

O objetivo do estudo é investigar a utilização de práticas de contabilidade gerencial (CG) na gestão de uma subsidiária brasileira, de indústria alemã de grande porte, identificando os benefícios esperados em determinadas decisões operacionais. O estudo oportuniza avaliar a aderência da empresa ao enfatizado pela literatura quanto à utilidade de tais práticas. Trata-se de uma pesquisa descritiva, cujos dados foram coletados no primeiro semestre de 2015, utilizando a técnica de pesquisa de profundidade in loco, mediante entrevistas com gestores, especialistas e analistas da empresa. A análise dos dados se deu de forma qualitativa e quantitativa, via cálculo do Ranking Médio das assertivas postas na forma de escalas do tipo Likert. Constatou-se que são utilizadas as 16 práticas elencadas, com diferentes graus de intensidade. Também, que as práticas tradicionais de CG são as mais utilizadas, destacando-se o orçamento anual e o custo padrão, em relação às contemporâneas como $\mathrm{ABC}$, custo-meta, análise $\mathrm{ABM}$, e determinantes de custos. Também foi verificado que a percepção do benefício das práticas tradicionais é maior do que das contemporâneas.

Palavras-chave: Gestão competitiva; Contabilidade gerencial; Gestão estratégica de custos;

\begin{abstract}
This article aims to investigate the use of managerial accounting practices (MAP) in the management of a Brazilian subsidiary, of large German industry, identifying the expected benefits of certain operational decisions. The study evaluates the company's adherence to the literature's emphasis about utility of such practices. This is a descriptive research, whose data were collected in the first half of 2015, using in-depth research technique through interviews with managers, specialists and analysts of the company. The data were analyzed qualitatively and quantitatively, by calculation the Average Ranking of the assertions placed in the form of Likert-scales type. It was verified that the 16 practices are used, with different degrees of intensities. In addition, the traditional MAP is the most used, standing out the annual budget and the standard cost, compared to the contemporary ones, such as $A B C$, target-cost, $A B M$ analysis, and cost determinants. It was also verified that the perception of the benefit of traditional practices is greater than the contemporary ones.
\end{abstract}

Keywords: Competitive management; Management accounting; Strategic cost management.
Letícia Jaqueline Hartz

Graduada em Ciências Contábeis pela Universidade do Vale do Rio dos Sinos (UNISINOS). Atividade Profissional: Analista de Controladoria. Contato: Av. Dr. Nilo Peçanha, 1600, Boa Vista, Porto Alegre (RS), CEP 91330-002. E-mail: leticiajaquelinehartz@gmail.com.

\section{Marcos Antônio de Souza}

Doutor em Controladoria e Contabilidade pela Universidade de São Paulo (FEA/ USP). Mestre em Administração pela Universidade Metodista de São Paulo (UNIMESP). Especialista em Administração Financeira e Controladoria (UNIMARCO). Graduado em Administração de Empresas pelo Centro Universitário Anhanguera (UNIA). Docente dos cursos de Mestrado e Doutorado em Ciências Contábeis na Universidade Federal de Uberlândia (UFU). Contato: Rua Brigadeiro Galvão, 436, apto. 25, Barra Funda, São Paulo (SP), CEP: 01151-000. E-mail: souza. marcosas@gmail.com

\section{Débora Gomes de Gomes} Doutora em Ciências Contábeis e Administração pela Universidade Regional de Blumenau (FURB). Mestre em Ciências Contábeis pela Universidade do Vale do Rio dos Sinos (UNISINOS). Graduada em Ciências Contábeis pela Universidade Católica de Pelotas (UCPEL). Docente dos cursos de Graduação e Mestrado em Ciências Contábeis da Universidade Federal do Rio Grande (FURG). Contato: Rua Karlo Harazin, 71, Vila São Jorge, Rio Grande, (RS), CEP 96.203-210. E-mail: debora_furg@yahoo.com.br 


\section{INTRODUÇÃO}

Dada a realidade de um cenário mercadológico dinâmico, marcado por grandes mudanças, complexidade acentuada e maiores incertezas, ganha maior destaque a preocupação dos gestores sobre análise, planejamento e desenvolvimento de projeções que assegurem a viabilidade dos negócios. Souza, Lisboa e Rocha (2003) enfatizam, nesse contexto, que a informação dentro do ambiente organizacional ganhou maior relevância ainda e passou a ser considerada como um dos elementos chaves para o sucesso. Andrade et al. (2013) corroboram que o ambiente das empresas é marcado por diversas mudanças e desafios, ensejando a necessidade da utilização de práticas que disponibilizem informações úteis e relevantes para o planejamento e controle de uma gestão mais eficaz.

Com maior antecedência, Iudícibus (1996) já dissertava que as práticas de contabilidade gerencial serviam como importantes ferramentas para auxílio da administração, com seus relatórios apoiando o planejamento, a execução e o controle da gestão organizacional. Iudícibus acrescentou que o uso de práticas de Contabilidade Gerencial (CG) não era recente e, ao contrário, era algo que algumas organizações já faziam há bastante tempo, e que tais práticas se aperfeiçoam e se alteram de acordo com as necessidades das empresas. Práticas que surgiram mais recentemente, que no conjunto integram a denominada gestão estratégica de custos (GEC), são consideradas mais apropriadas para um ambiente diferente daquele existente quando práticas mais tradicionais foram desenvolvidas (SHANK, 1989; TURNEY; ANDERSON, 1989; COOPER; SLAGMULDER, 2003).

Esse reconhecimento da utilidade das práticas e informações oriundas da CG motivou o surgimento de estudos direcionados a investigar o uso efetivo dessas informações. Souza, Lisboa e Rocha (2003) desenvolveram uma pesquisa sobre tal uso com controllers de subsidiárias brasileiras de empresas multinacionais e não encontraram utilização acentuada. Schwarze, Wullenweber e Hackethal (2008), em pesquisa com bancos instalados em países de língua alemã, mostram que a mudança na CG é impulsionada pelas expectativas do conselho de administração, pela transparência e pela lucratividade. Verifica-se, por êsses exemplos, que a preocupação com o estudo do tema é relevante também em outros segmentos, tas como o de serviços, que não apenas as empresas industriais e comerciais.

Abdel-Maksoud (2011) identificou relação positiva entre o uso de avançadas técnicas de manufatura com práticas avançadas de CG em empresas industriais egípcias. Souza e Gasparetto (2017), em pesquisa com gestores de empresas brasileiras inovadoras, destacam que a escolha pela adoção de práticas de CG pode ocorrer por diversos motivos, inclusive pelas características dos gestores organizacionais. Outros estudos empíricos internacionais (ABDEL-KADER; LUTHER, 2006; DUGDALE, JONES; GREEN, 2006; OGUNGBADE, 2016) também foram desenvolvidos com o objetivo de investigar o uso de práticas de CG pelas empresas, analisando-o comparativamente ao que estabelecem os estudos teóricos.

A análise dessas e de outras pesquisas relacionadas à adoção de práticas de CG identifica a necessidade de se investigar também a relação do seu uso associado a decisões operacionais específicas, suas utilidades e benefícios.

Dado esse contexto, o problema de pesquisa proposto neste estudo é: quais as principais práticas de contabilidade gerencial adotadas em uma empresa industrial gaúcha de grande porte em função das suas utilidades e benefícios? Tem-se assim que o objetivo do estudo está relacionado a investigar a utilização de práticas de CG na gestão empresarial, focalizando tal uso não de forma genérica, mas sim em decisões específicas e em função das dificuldades e dos esperados benefícios de sua aplicação. O estudo justifica-se como forma de avaliar a aderência e validação dada pela empresa às práticas de CG, tradicionais e contemporâneas, recomendadas pela literatura como as mais apropriadas e benéficas para a realidade de decisões operacionais específicas e em um mercado competitivo e exigente.

Este estudo contribui para a validação da teoria desenvolvida ou mesmo para repensar sobre a praticidade das práticas contábeis estabelecidas. Um exemplo desse tipo de validação é comprovado no estudo de Kaplan e Anderson (2007), destinado ao desenvolvimento do Time Driven Activity Based Costing (TDABC), ao trazer o reconhecimento de que pesquisas realizadas com empresas identificaram a necessidade de mudança em conceitos e práticas estruturais do método de custeio original Activity Based Costing (ABC). O estudo de Weetman (2006) também sustenta a realização de estudos desta natureza. Segundo o autor, eles fornecem uma oportunidade para discutir a relevância das teorias desenvolvidas sob determinados argumentos.

Esse entendimento corrobora a posição de Iudícibus (1996), segundo o qual a doutrina tem relevância quando ajuda a entender melhor e explicar a prática, eventualmente quando consegue projetar estruturas conceituais que se antecipem à prática, mas que devem ser validadas por experimentos reais. As contribuições do estudo também estão amparadas no entendimento dado por Gomes (1995), para o qual o confronto da teoria com a prática nesses novos cenários mais do que se justifica, como tentativa para se evitar que o senso comum prevaleça na apresentação dos novos enfoques como panaceia para a maioria dos problemas encontrados nos sistemas de controles de gestão dos diversos tipos de organização.

\section{REFERENCIAL TEÓRICO}

\subsection{PRÁTICAS DE CONTABILIDADE GERENCIAL}

Diversas práticas, procedimentos ou técnicas têm sido desenvolvidas ao longo do tempo no âmbito da Contabilidade Gerencial (CG), o que ocorreu com base em metodologias consideradas no seu tempo como as mais apropriadas 
à sustentabilidade dos negócios. Sobre isso, Frezatti (2005, p. 24) enfatiza que "a reciclagem de um conceito é algo que pode acontecer ao longo dos tempos".

Esse entendimento enfatiza que um conceito, depois de algum tempo, precisa ser repensado, revisado, algumas vezes ampliado e, em alguns casos, esquecido. É isso o que tem marcado a formação dos dois conjuntos de práticas de CG, as tradicionais e as contemporâneas. Para melhor apresentação elas foram divididas em bois blocos: um dedicado às tradicionais e outro às contemporâneas.

\subsubsection{Práticas Tradicionais de Contabilidade Gerencial}

Uma apropriada forma de identificação e classificação das práticas tradicionais de CG se dá mediante visita a obras específicas sobre o respectivo desenvolvimento teórico, bem como pela consulta a pesquisas empíricas. Dada a quantidade dessas práticas, um recorte se faz necessário, visando manter a objetividade do estudo (Quadro 1).

Mesmo sendo discutível, este é um procedimento rotineiramente adotado nas pesquisas sobre o tema. A literatura sobre tais práticas é farta. Muitas dessas obras baseiam-se no trabalho abrangente realizado pelo IFAC (1998), o qual sistematizou os estágios e classificação das principais práticas discutidas em pesquisas.

Quadro 1 - Práticas Tradicionais de Contabilidade Gerencial

\begin{tabular}{|c|c|c|}
\hline Denominação da Prática & Significado & Literatura Base \\
\hline Métodos de Custeio & $\begin{array}{c}\text { Definição de quais e como os custos serão } \\
\text { alocados aos objetos de custeio (Absorção, } \\
\text { Variável, Direto). }\end{array}$ & $\begin{array}{c}\text { Martins (2010) } \\
\text { Pong e Mitchell (2006) }\end{array}$ \\
\hline Análise Custo-Volume-Lucro & $\begin{array}{l}\text { Impactos provocados no lucro em função do } \\
\text { volume e do comportamento dos custos (Margem } \\
\text { de Contribuição, Ponto de Equilíbrio, Margem } \\
\text { de Segurança Operacional - MSO e Grau de } \\
\text { Alavancagem Operacional - GAO). }\end{array}$ & $\begin{array}{l}\text { Garrison, Noreen e Brewer (2013); } \\
\text { Blocher et al. (2007) }\end{array}$ \\
\hline $\begin{array}{l}\text { Análise de Resultado por } \\
\text { Unidade de Negócio }\end{array}$ & $\begin{array}{l}\text { Mensuração do resultado gerado por cada divisão } \\
\text { operacional da empresa (Custeio Direto). }\end{array}$ & $\begin{array}{l}\text { Warren, Reeve e Fess (2008) } \\
\text { Solomons (1965) }\end{array}$ \\
\hline Custo Padrão & $\begin{array}{l}\text { Custo que deveria ocorrer caso as operações } \\
\text { fossem realizadas com a eficiência planejada. }\end{array}$ & $\begin{array}{c}\text { Garrison, Noreen e Breer (2013); Marie et } \\
\text { al. (2010) }\end{array}$ \\
\hline Planos Orçamentários & $\begin{array}{l}\text { Planejamento estratégico e orçamentos } \\
\text { operacionais (Budget) criados para embasar e } \\
\text { direcionar o processo decisório. }\end{array}$ & $\begin{array}{l}\text { Khan e Khalique (2014) } \\
\text { Temtime (2003) }\end{array}$ \\
\hline Medidas de Retorno & $\begin{array}{l}\text { Indicadores das diversas formas de retornos providas } \\
\text { pela análise das demonstrações contábeis (Retorno } \\
\text { Sobre Ativos, Retorno sobre Patrimônio Líquido). }\end{array}$ & $\begin{array}{l}\text { Hoji (2014) } \\
\text { Solomons (1965) }\end{array}$ \\
\hline Análise de Lucratividade & $\begin{array}{l}\text { Indicadores das diversas formas de lucros providas } \\
\text { pela análise das demonstrações contábeis (Lucro } \\
\text { Bruto, Lucro Operacional, Lucro Líquido) }\end{array}$ & $\begin{array}{c}\text { Assaf (2012) } \\
\text { Bhimani et al. (2015) }\end{array}$ \\
\hline Análise Econômica Investimento & $\begin{array}{c}\text { Técnica para avaliação da viabilidade econômica } \\
\text { de novos investimentos (Fluxo de Caixa, Valor } \\
\text { Presente Líquido, Taxa Interna de Retorno, } \\
\text { Payback period). }\end{array}$ & $\begin{array}{l}\text { Ross et al. (2015) } \\
\text { Ghahremani, Aghaie e Abedzadeh (2012) }\end{array}$ \\
\hline Precificação de Produto & $\begin{array}{l}\text { Critérios e bases utilizadas no cálculo do preço de } \\
\text { venda (baseado em custos + margem). }\end{array}$ & $\begin{array}{l}\text { Garrison, Noreen e Brewer (2013) } \\
\text { Hansen e Mowen (2001) }\end{array}$ \\
\hline
\end{tabular}

Fonte: Elaborado a partir da literatura citada.

\subsubsection{Práticas Contemporâneas de Contabilidade Gerencial}

Nesta parte são apresentadas as práticas contemporâneas de CG, que no seu conjunto formam a denominada GEC e a Contabilidade Gerencial Estratégica (CGE). O surgimento de tais práticas se deve, segundo Turney e Anderson (1989), da necessidade de evolução e atualização de conceitos, pois aquelas práticas tradicionais foram úteis para um macro ambiente de negócios que passou por mudanças significativas. Os autores acrescentam que a nova realidade ambiental passou a exigir informações gerenciais contábeis mais apropriadas.

Ainda segundo Turney e Anderson (1989), tem-se nesse reconhecimento um processo de melhoria contínua na capacidade da contabilidade gerar informações úteis e oportunas. Também aqui as práticas estão circunscritas à identificação e seleção daquelas mais pesquisadas e das respectivas fontes (Quadro 2). 
Quadro 2 - Práticas Contemporâneas de Contabilidade Gerencial

\begin{tabular}{|c|c|c|}
\hline Denominação da Prática & Significado & Literatura Base \\
\hline Análise das Atividades & $\begin{array}{l}\text { Uso das atividades como instrumento de gestão: } \\
\text { Método de Custeio Baseado em Atividades (ABC) e } \\
\text { Time-driven Activity-Based Costing (TDABC); Activity- } \\
\text { Based Management (ABM). }\end{array}$ & $\begin{array}{l}\text { Kaplan e Anderson (2007) } \\
\text { Blocher et al. (2007) } \\
\text { Brimson (1996) }\end{array}$ \\
\hline Análise dos Custos Logísticos & $\begin{array}{l}\text { Mensuração e análise dos custos da logística de } \\
\text { entrada (inbound), do processo (produção), outbound } \\
\text { (distribuição) e reversa (retornos). }\end{array}$ & $\begin{array}{l}\text { Faria e Costa (2012) } \\
\text { Zhao e Tang (2009) } \\
\text { Zeng e Rossetti (2003) }\end{array}$ \\
\hline Custo-Meta & $\begin{array}{l}\text { Custo baseado nos preços de mercado e na margem de } \\
\text { lucro planejada (Custo Alvo). }\end{array}$ & $\begin{array}{l}\text { Camacho e Rocha (2008) } \\
\text { Swenson et al. (2003) } \\
\text { Sakurai (1997) }\end{array}$ \\
\hline $\begin{array}{l}\text { Análise dos Custos da } \\
\text { Qualidade }\end{array}$ & $\begin{array}{l}\text { Mensuração e análise dos custos decorrentes da gestão } \\
\text { do sistema da qualidade. }\end{array}$ & $\begin{array}{l}\text { Blocher et al. (2007) } \\
\text { Jeffrey (2004) } \\
\text { Hansen e Mowen (2001) }\end{array}$ \\
\hline Análise dos Custos Ambientais & $\begin{array}{l}\text { Mensuração e análise dos custos decorrentes da gestão } \\
\text { ambiental interna e externa. }\end{array}$ & $\begin{array}{c}\text { Kocsis e Bem (2012) } \\
\text { Keitel (2011) } \\
\text { Hansen e Mowen (2001) }\end{array}$ \\
\hline $\begin{array}{l}\text { Análise do Desempenho de } \\
\text { Concorrentes }\end{array}$ & $\begin{array}{l}\text { Mensuração de custos, resultados e principais } \\
\text { indicadores do desempenho de concorrentes. }\end{array}$ & $\begin{array}{l}\text { Anderson e Guilding (2006) } \\
\text { Hoffjan e Heinen (2005) } \\
\text { Cooper e Slagmulder (2004) }\end{array}$ \\
\hline $\begin{array}{l}\text { Análise do Desempenho com } \\
\text { Clientes }\end{array}$ & $\begin{array}{l}\text { Mensuração das receitas, custos e resultados } \\
\text { alcançados com principais clientes. }\end{array}$ & $\begin{array}{l}\text { Foster, Gupta e Sjoblom (1997) } \\
\text { Raaj, Vernooj e Triest (2003) }\end{array}$ \\
\hline $\begin{array}{l}\text { Fatores Determinantes de } \\
\text { Custos }\end{array}$ & $\begin{array}{l}\text { Análise dos fatores que determinam a ocorrência de } \\
\text { custos, conforme estrutura operacional adotada. }\end{array}$ & $\begin{array}{l}\text { Carneiro (2015) } \\
\text { Pivru et al. (2012); } \\
\text { Shank (1989) }\end{array}$ \\
\hline Análise de Custos de Setups & $\begin{array}{l}\text { Mensuração e análise dos custos da preparação de } \\
\text { ferramental e equipamento do processo produtivo. }\end{array}$ & $\begin{array}{l}\text { Faria e Costa (2012) } \\
\text { Perkins (2004) } \\
\text { Shingo (2000); Harmon (1991) }\end{array}$ \\
\hline Precificação de Produto & $\begin{array}{l}\text { Critérios e bases utilizadas no cálculo do preço de } \\
\text { venda (Base no Mercado, Custo Meta). }\end{array}$ & $\begin{array}{l}\text { Lucas e Rafferty (2008) } \\
\text { Snelgrove (2011) } \\
\text { Blocher et al. (2007) }\end{array}$ \\
\hline
\end{tabular}

Fonte: Elaborado a partir da literatura citada.

\subsection{Percepções de Utilidades e Benefícios de Práticas de CG}

A literatura relacionada a gestão organizacional e por áreas de conhecimento direcionadas a dotar o processo decisório de instrumentos que potencializem os resultados, é fértil em atribuir às práticas de CG como insumo necessário à eficácia organizacional, atribuindo-lhes diversos estágios de evolução (IFAC, 1998). As iniciativas em manter a CG apta a atender as demandas que surgem e se alteram ao longo do tempo tem direcionado esforços ao seu desenvolvimento e atualização (TURNEY; ANDERSON, 1989).

A par desse posicionamento a respeito da utilidade e contribuição da CG como suporte ao processo decisório das organizações, a efetiva utilização das suas práticas tem pautado o desenvolvimento de estudos direcionados a identificar fatores que podem interferir na aceitação delas ou não (RUSSO; GUERREIRO, 2017a). Pesquisas tem demonstrado que a abordagem da Teoria Institucional pode contribuir para a compreensão das práticas de CG (BURNS; SCAPENS, 2000; GUERREIRO et al. 2005). Duas vertentes têm dominado as discussões sobre a Teoria Institucional. A primeira, a Nova Economia Institucional, estuda os relacionamentos entre organizações e o ambiente em que estão inseridas (COASE, 1937; WILLIAMSON, 1971). A segunda, a Velha Economia Institucional estuda o microprocesso de institucionalização, ou seja, hábitos que se transformam em rotinas e estas, por sua vez, em instituições (BARLEY; TOLBERT, 1997; BURNS; SCAPENS, 2000). Pesquisas empíricas têm sido desenvolvidas sobre a temática (RUSSO; GUERREIRO, 2017b; FILIPINI et al. 2018; YAP et al. 2013; AHMAD, 2014). Nesses estudos, a utilização dos princípios da Teoria Institucional é geralmente direcionada a identificar a adoção das tradicionais e/ou contemporâneas práticas de CG.

Quanto à utilização das informações da CG, estudos específicos (ATKINSON et al. 2000; GARRISON; NOREEN; BREWER, 2013; BHIMANI et al. 2015) destacam os benefícios relacionados a decisões sobre precificação de produtos, planejamento e controle de custos, análise de lucratividade de produto, definição de níveis de atividades para alcance de resultados planejados, elaboração de orçamentos, etc. De outra parte, estudos empíricos (MUNIZ, 2010; YAP et al., 2013; AHMAD, 2014) têm identificado, a respeito das práticas de CG, argumentos sobre dificuldades e complexidades de implan- 
tação e uso, não identificação objetiva dos benefícios e falta de expertise dos gestores como fatores restritivos à adoção das práticas de CG, principalmente das chamadas contemporâneas. Em consequência, aquelas práticas rotuladas de tradicionais tem-se mostrado mais presentes na prática empresarial (TEIXEIRA et al. 2011; DUGDALE; JONES; GREEN, 2006).

\subsection{Estudos Relacionados}

Dada a realidade de aparente falta de simetria entre os argumentos teóricos e os achados de pesquisas empíricas, novos esforços têm sido direcionados à identificação sobre a utilização efetiva das práticas de CG na realidade das empresas. A procura por identificar aquelas práticas utilizadas em relação a decisões específicas são formas de dar encaminhamento em direção a maiores esclarecimentos a essa situação.

Nesse sentido, pesquisas empíricas nacionais e internacionais ratificam a relevância e oportunidade do tema. Nos estudos selecionados prevalece o foco comparativo entre as práticas tradicionais e as contemporâneas, estas últimas com um foco estratégico de onde emergiu a Contabilidade Gerencial e Estratégica (CGE) e a Gestão Estratégica de Custos (GEC).

A seleção de estudos nacionais ou internacionais procurou ser consistente em selecionar estudos com empresas industriais e de porte semelhante (grande ou médio). Outro critério considerado foi a metodologia básica de coleta e análise dos dados, ou seja, a coleta deu-se prioritariamente por meio de entrevistas ou survey, dependendo do tamanho da amostra.

Além disso, cuidou-se também para que outras semelhanças fossem privilegiadas. Uma delas é a quantificação percentual das práticas mais utilizadas, classificando-as em tradicionais e contemporâneas. Igualmente, a seleção de quais práticas pesquisar deu-se a partir de consulta à literatura que trata do tema. Enfim, apesar de não haver igualdade absoluta entre metodologia, objetivos e práticas analisadas, dada a variedade existente, procurou-se selecionar estudos o mais próximo possível do perfil da empresa pesquisada. Somente assim os resultados podem ser comparáveis, ainda que parcialmente.

A análise dos resultados encontrados nos estudos pesquisados relaciona-os com o que estabelece a literatura a respeito da utilidade que as práticas pesquisadas trazem de contribuição à gestão empresarial. Tem-se também estudos que, além de focar nessa análise comparativa abordam também possíveis causas da adoção ou não. Destaca-se que a contabilidade gerencial compreende um leque variado de práticas, dentre as quais ganha destaque as relacionadas à mensuração, planejamento e controle de custos.

\subsubsection{Estudos Nacionais}

Resume-se no Quadro 3 os estudos nacionais selecionados via pesquisa livre na internet. Por esse quadro é possível a visualização geral desses estudos em seus aspectos principais.

Quadro 3 - Estudos Nacionais Relacionados

\begin{tabular}{|c|c|c|}
\hline Autor e Ano & Objetivo & Principais Achados \\
\hline Souza, Lisboa e Rocha (2003). & $\begin{array}{l}\text { Analisar a adoção de práticas de contabilidade } \\
\text { gerencial por parte das empresas. }\end{array}$ & $\begin{array}{l}\text { Predomina a utilização de práticas tradicionais } \\
\text { de contabilidade gerencial. }\end{array}$ \\
\hline $\begin{array}{l}\text { Reckziegel, Souza e Diehl } \\
\text { (2007) }\end{array}$ & $\begin{array}{l}\text { Identificar as práticas de gestão de custos pelas } \\
\text { empresas. }\end{array}$ & $\begin{array}{l}\text { As empresas não têm aderido às novas ou } \\
\text { aperfeiçoadas práticas de gestão de custos. }\end{array}$ \\
\hline Oyadomari et al (2008). & $\begin{array}{l}\text { Entender a adoção de artefatos de contabilidade } \\
\text { gerencial por empresas brasileiras. }\end{array}$ & $\begin{array}{l}\text { Práticas mais utilizadas: planej. estratégico, } \\
\text { ROI, EBITDA, Resultado por Unidade de } \\
\text { Negócios. }\end{array}$ \\
\hline Souza, Fontana e Boff (2010). & $\begin{array}{l}\text { Investigar adoção de práticas de planejamento } \\
\text { e controle de custos por indústrias da cidade de } \\
\text { Caxias do Sul. }\end{array}$ & $\begin{array}{l}\text { Expressiva utilização de práticas recentes } \\
\text { (custo-meta) e de práticas tradicionais (custo- } \\
\text { padrão). }\end{array}$ \\
\hline Muniz (2010). & $\begin{array}{l}\text { Investigar a adoção de práticas de gestão } \\
\text { estratégica de custos (GEC) por grandes } \\
\text { empresas brasileiras. }\end{array}$ & $\begin{array}{l}\text { A maior barreira é a baixa percepção dos } \\
\text { benefícios. Usos: custo-meta, padrão e } \\
\text { determinantes de custos. }\end{array}$ \\
\hline Teixeira et al (2011). & $\begin{array}{l}\text { Identificar se as empresas do Espírito Santo } \\
\text { utilizam artefatos modernos de contabilidade } \\
\text { gerencial. }\end{array}$ & $\begin{array}{l}\text { As empresas do Espírito Santo utilizam } \\
\text { ferramentas tradicionais de contabilidade } \\
\text { gerencial. }\end{array}$ \\
\hline Andrade et al. (2013). & $\begin{array}{l}\text { Identificar a intensidade de percepção e de } \\
\text { práticas de CG estratégica (CGE) pelos gestores. }\end{array}$ & $\begin{array}{l}\text { Percepção elevada das práticas pelos gestores } \\
\text { (custo-meta, benchmarking, custeio e preços). }\end{array}$ \\
\hline Souza e Gasparetto (2017). & $\begin{array}{l}\text { Verificar quais as práticas de CG utilizadas por } \\
\text { empresas inovadoras. }\end{array}$ & $\begin{array}{l}\text { Intensidade de práticas tradicionais de } \\
\text { segundo estágio: breakeven, orçamento e } \\
\text { lucro por produto. }\end{array}$ \\
\hline
\end{tabular}




\begin{tabular}{|c|l|l|}
\hline Autor e Ano & Objetivo & $\begin{array}{l}\text { Principais Achados } \\
\text { Russo e Guerreiro (2017a). }\end{array}$ \\
$\begin{array}{l}\text { Compreender a percepção dos gestores sobre a } \\
\text { sociomaterialidade de práticas de CG } \\
\text { Russo e Guerreiro (2017b). }\end{array}$ & $\begin{array}{l}\text { Conhecer a percepção sobre as práticas de na resolução de } \\
\text { contabilidade gerencial mais usadas por } \\
\text { empresas. }\end{array}$ & $\begin{array}{l}\text { Poucas empresas usam práticas de CG. } \\
\text { Prioridade de práticas de planej. e controle } \\
\text { (83,4\%). }\end{array}$ \\
Filipini et al. (2018). & $\begin{array}{l}\text { Verificar a utilidade da informação contábil na } \\
\text { tomada de decisão, na percepção dos gestores. }\end{array}$ & $\begin{array}{l}\text { Valorização da informação contábil; os estores } \\
\text { percebem a importância dela nas decisões. }\end{array}$ \\
\hline
\end{tabular}

Fonte: Elaborado a partir da literatura citada.

O que se observa nesses estudos, de forma geral, é a conclusão sobre a predominância no uso das chamadas práticas tradicionais de contabilidade gerencial. Essa sobreposição às práticas mais recentemente desenvolvidas é uma contra posição prática ao argumento de que o ambiente de maior complexidade e desafiador enseja a utilização de informações diferenciadas.

Tal predominância é flagrantemente contrária ao argumentado em obras contemporâneas sobre a utilização de informações que emergem da contabilidade gerencial, pois mostra que, para os gestores usuários de tais informações as práticas tradicionais de CG atendem as suas necessidades. Dentre os argumentos mais presentes, há a questão da complexidade de implantação e uso dessas novas informações, além dos investimentos necessários para investir em sistemas e em melhor capacitação nas habilidades dos geradores e usuários das informações daí resultantes.

Apesar de não ser o foco deste estudo, nota-se nesses trabalhos selecionados o entendimento de que aspectos da teoria institucional podem explicar, pelo menos em parte, a adoção de práticas mais contemporâneas, quando ela ocorre. Nesse sentido, porte e exposição da empresa a um ambiente globalizado de maior concorrência, mesmo em países de economia mais desenvolvida, não se confirma como indutores à maior utilização de práticas contemporâneas como advoga a literatura.

De outra parte, investimentos em modus operandi mais eficientes, tais como a computação e automação de processos, parece atrair maior atenção dos gestores, apesar de mantida a predominância de práticas tradicionais de CG. Essa aparente dicotomia é mais uma divergência em relação aos já citados argumentos presentes na literatura mais recente que trata de instrumentos e técnicas da CG na gestão das empresas.

\subsubsection{Estudos Internacionais}

Os estudos internacionais selecionados são apresentados no Quadro 4. Também aqui pode-se identificar os aspectos principais tratados nesses estudos. Vale para esse conjunto de estudos internacionais os mesmos argumentos apresentados na seção anterior relativamente aos estudos nacionais.

Especial destaque é dado em alguns estudos desenvolvidos em países de expressão econômica mais reduzida, nos quais tem-se a menor adoção de práticas contemporâneas em relação àquelas tradicionais. Observa-se também que nesses estudos é destacado que seus achados são corroborados por estudos realizados com empresas de países economicamente mais desenvolvidos. Ou seja, essa característica ambiental parece não interferir na decisão de, em sua maioria, dar preferência ao uso de práticas tradicionais de CG.

Quadro 4 - Estudos Internacionais Relacionados

\begin{tabular}{|c|l|l|}
\hline Autor e Ano & $\begin{array}{l}\text { Objetivo } \\
\text { Abdel-Kader e Luther (2006) } \\
\text { Investigar o uso de práticas de CG em 148 (de } \\
650 \text { ) empresas britânicas do setor de alimentos } \\
\text { e bebidas. }\end{array}$ & $\begin{array}{l}\text { Principais Achados } \\
\text { Predominância das práticas tradicionais. Evi- } \\
\text { dente distanciamento entre a teoria e a prática } \\
\text { nas empresas. } \\
\text { Dugdale, Jones e Green (2006) } \\
\text { Investigar práticas contemporâneas de Contabili- } \\
\text { dade Gerencial em 41 indústrias inglesas, } \\
\text { complementas às tradicionais (M. Contrib, } \\
\text { Custo-padrão, Budget) }\end{array}$ \\
$\begin{array}{c}\text { Angelakis, Theriou e Floro- } \\
\text { poulo (2010) }\end{array}$ & $\begin{array}{l}\text { Investigar a extensão de uso de práticas tradicio- } \\
\text { nais e atuais de CG por grandes indústrias gregas } \\
\text { e os benefícios obtidos. } \\
\text { Investigar relação entre novos modos de pro- } \\
\text { dução (comput. \& autom.) e práticas avançadas } \\
\text { de CG em indústrias do Egito. }\end{array}$ & $\begin{array}{l}\text { Pradicaicionais. As principais são as de avaliação } \\
\text { te desempenho. }\end{array}$ \\
$\begin{array}{l}\text { Forte correlação positiva entre novos modos } \\
\text { de produção e avançadas práticas de CG em } \\
\text { 240 empresas }\end{array}$
\end{tabular}




\begin{tabular}{|c|c|c|}
\hline Autor e Ano & Objetivo & Principais Achados \\
\hline Albu e Albu (2012) & $\begin{array}{l}\text { Investigar pela lente da teoria de contingência o } \\
\text { uso de práticas atuais de CG em } 109 \text { empresas } \\
\text { da Romênia. }\end{array}$ & $\begin{array}{l}\text { Capital estrangeiro e porte são fatores de } \\
\text { adoção. Fatores de competição dados pela } \\
\text { teoria são rejeitados. }\end{array}$ \\
\hline Yap et al, (2013) & $\begin{array}{l}\text { Identificar quais tipos de práticas de CG são } \\
\text { adotadas em } 118 \text { empresas da Malásia. Razões } \\
\text { de utilização ou não. }\end{array}$ & $\begin{array}{l}\text { Prevalece a adoção de práticas tradiciona- } \\
\text { is. Gestores não entendem a utilidade das } \\
\text { contemporâneas: complexas para implantar } \\
\text { e utilizar. }\end{array}$ \\
\hline Ahmad (2014) & $\begin{array}{l}\text { Examinar a extensão do uso de tradicionais e } \\
\text { avançadas de CG em indústrias da Líbia. }\end{array}$ & $\begin{array}{l}\text { Predominância de práticas tradicionais, igual a } \\
\text { pesquisas em países desenvolvidos. Barreiras: } \\
\text { fatores institucionais e complexidade. }\end{array}$ \\
\hline Ogungbade (2016) & $\begin{array}{l}\text { Investigar o estágio de adoção de modernas } \\
\text { técnicas de CG entre } 43 \text { indústrias do Quênia. }\end{array}$ & $\begin{array}{l}\text { É baixo o uso das novas técnicas de CG. As } \\
\text { tradicionais são mais presentes. Falta apoio } \\
\text { dos gestores. }\end{array}$ \\
\hline $\begin{array}{l}\text { Leite, Fernandes e Leite } \\
\qquad(2015)\end{array}$ & $\begin{array}{l}\text { Verificar relacionamento entre uso de práticas de } \\
\text { CG e diversos fatores contingenciais por empre- } \\
\text { sas de Portugal. }\end{array}$ & $\begin{array}{l}\text { Predominam as práticas tradicionais, mesmo } \\
\text { nas situações em que a teoria enfatiza a utili- } \\
\text { dade das avançadas. }\end{array}$ \\
\hline Bangara (2017) & $\begin{array}{l}\text { Analisa as práticas de CG adotadas por } 759 \\
\text { grandes indústria localizadas em Nairobi (Kenya) } \\
\text { e suas principais causas. }\end{array}$ & $\begin{array}{l}\text { A adoção é função do macro ambiente interno } \\
\text { e externo. Utilizam tanto práticas avançadas } \\
\text { como tradicionais. }\end{array}$ \\
\hline
\end{tabular}

Fonte: Elaborado a partir da literatura citada.

\section{PROCEDIMENTOS METODOLÓGICOS}

Quanto à classificação metodológica, a presente pesquisa, no que se refere aos seus objetivos, caracteriza-se como pesquisa descritiva, pois o estudo circunscreve-se a descrever o uso de práticas de contabilidade gerencial considerando a sua utilidade e benefícios percebidas pelos respondentes (CERVO; BERVIAN; SILVA, 2007). Para realização da pesquisa descritiva foi utilizada a técnica de pesquisa de profundidade in loco. Conforme Hair et al. (2005), uma pesquisa em profundidade é uma seção de discussão realizada com a utilização de um instrumento de pesquisa.

Quanto à abordagem do problema, a pesquisa utiliza análise quantitativa e qualitativa. Quantitativa porque transforma em números as opiniões e informações coletadas, ainda que não utilize sofisticadas técnicas estatísticas. E qualitativa pois procura dar interpretação e significado aos dados coletados e tratados para além da sua quantificação (SILVA; MENEZES, 2005).

A coleta de dados foi realizada por entrevistas, com auxílio de instrumento de pesquisa, com questões basicamente semiestruturadas e abertas, oportunizando que o respondente relatasse as informações requeridas. A validação desse instrumento deu-se com três profissionais experientes no tema, que não participaram da amostra final. Esse pré-teste oportunizou implementar melhorias nos enunciados do instrumento. Para as assertivas relativas à utilização, benefícios e impactos, optou-se pelo uso das escalas do tipo Likert de cinco pontos (HAIR et al., 2005).

Para as assertivas sobre o uso ou não das práticas a escala 1 se refere à "não utilização", e a 5 "utiliza intensamente". Para as questões relacionadas aos benefícios e dificuldades de utilização das práticas, 1 significa "nenhum" e 5 "muito elevado". Na questão de múltipla escolha, usada para verificar a utilização das práticas de CG na tomada de decisão, o respondente escolhia até três opções de práticas para cada decisão. Outras informações foram obtidas diretamente no endereço eletrônico e em documentos de uso interno da empresa.

A partir da coleta dos dados realizou-se a análise quantitativa e qualitativa dos dados, tabulando-os primeiramente em planilha eletrônica. A análise quantitativa foi realizada por meio do cálculo do ranking médio (RM) das escalas, de acordo com Oliveira (2005). O RM é representado pela ponderação das escalas em função das opções apresentadas a cada uma delas. Assim, o RM mostra a média das respostas e representa a indicação conjunta do grupo de entrevistados. Para melhor análise dos dados as práticas de CG foram divididas em dois grupos conforme Quadro 1 (práticas tradicionais) e Quadro 2 (práticas contemporâneas).

\subsection{PERFIL DA ENTIDADE OBJETO DA PESQUISA}

A empresa objeto do estudo é uma subsidiária brasileira de uma multinacional alemã de grande porte, fundada na década de 1920, atuante no segmento metalúrgico e com unidades de fabricação em mais de 160 países. A subsidiária brasileira foi criada na década de 1970, no Rio Grande do Sul e tem cerca de 2.200 funcionários. Ela conta com um amplo portfólio de produtos, e investe fortemente em inovações tecnológicas, modernização de seus processos e desenvolvimento de novos produtos, assegurando que a marca seja conhecida pela excelência e qualidade. Conta com certificações ISO 14001, OHSAS 18001 e ISO 9001. 
O faturamento anual da empresa é acima de R $\$ 2$ bilhões, $45 \%$ decorrente de exportações para clientes da América Latina e para as empresas coligadas. As cotas de exportação e os mercados são definidos pela matriz, atendendo a uma estratégia de globalização e com base em aspectos de competitividade. O Grupo é líder em seu segmento, detendo 30\% do mercado mundial e $75 \%$ do brasileiro.

A unidade brasileira tem sua capacidade de produção dividida em dois segmentos de negócio: (a) Segmento Alfa, cuja finalidade é a fabricação de produtos para atender os mercados nacional e internacional; (b) Segmento Gama, cuja finalidade é a fabricação de componentes para atender a demanda mundial das empresas do grupo.

Verifica-se por esse breve perfil que a empresa reúne os atributos destacados na literatura sobre a contabilidade gerencial (JOHNSON; KAPLAN, 1987; COOPER; SLAGMULDER, 2003; 2004) quando realça a utilidade e benefícios de práticas de CG, ou seja, empresas com porte significativo, variado mix de produto, avançada tecnologia de processo, atuante em mercado de elevada concorrência, dentre outros fatores.

\subsection{PERFIL DOS RESPONDENTES}

Foram selecionados para participar da pesquisa os profissionais das seguintes áreas: custos de produção dos segmentos alfa e gama, controladoria e marketing. A escolha desses profissionais se deu com base na indicação do Controller da empresa, dado que eles fazem uso de práticas de CG nas suas atividades e são os responsáveis pela definição e implementação de práticas para a gestão da empresa.

Conforme apresentado no Quadro 3, os respondentes possuem formação acadêmica superior completa e apenas dois deles não têm formação em pós-graduação. O tempo médio de atuação deles na empresa e de experiência na função é de 15 anos. Dessa forma, eles têm perfil adequado para participar da pesquisa pois estão a tempo suficiente para conhecer com profundidade as práticas adotadas na empresa, bem como suas metodologias, benefícios, dificuldades e impactos.

Quadro 5 - Perfil dos Respondentes

\begin{tabular}{|c|c|c|c|}
\hline Função & Formação acadêmica & $\begin{array}{c}\text { Tempo de atuação } \\
\text { na empresa }\end{array}$ & $\begin{array}{c}\text { Tempo de experiência } \\
\text { na função }\end{array}$ \\
\hline $\begin{array}{l}\text { Especialista em Custos } \\
\text { Segmento Alfa }\end{array}$ & $\begin{array}{c}\text { Administração de Empresas com } \\
\text { ênfase em finanças }\end{array}$ & 5 anos & 10 anos \\
\hline $\begin{array}{l}\text { Especialista em Custos } \\
\text { Segmento Gama }\end{array}$ & $\begin{array}{l}\text { Engenharia Mecânica } \\
\text { MBA em Administração da produção }\end{array}$ & 6 anos & 6 anos \\
\hline Supervisor de Controladoria & $\begin{array}{l}\text { Ciências Contábeis } \\
\text { MBA em Controladoria }\end{array}$ & 18 anos & 3 anos \\
\hline $\begin{array}{l}\text { Especialista em Custos e } \\
\text { Controladoria }\end{array}$ & $\begin{array}{l}\text { Ciências Contábeis } \\
\text { MBA em Controladoria }\end{array}$ & 18 anos & 5 anos \\
\hline $\begin{array}{c}\text { Especialista em } \\
\text { Orçamento e } \\
\text { Controladoria }\end{array}$ & $\begin{array}{l}\text { Administração de Empresas } \\
\text { MBA em Finanças empresariais } \\
\text { Mestrado em Controladoria }\end{array}$ & 29 anos & 35 anos \\
\hline $\begin{array}{l}\text { Analista de Custos e } \\
\text { Controladoria }\end{array}$ & Administração de Empresas & 29 anos & 39 anos \\
\hline Analista de Marketing & $\begin{array}{l}\text { Engenharia de Produção } \\
\text { Mestrado em Engenharia de Produção }\end{array}$ & 3 anos & 5 anos \\
\hline
\end{tabular}

Fonte: Dados da pesquisa.

\subsection{LIMITAÇÕES DO ESTUDO}

A primeira limitação do estudo diz respeito à restrição imposta pela empresa quanto ao maior acesso aos relatórios gerenciais, limitando-o a relatórios específicos sobre o tema da pesquisa e após crivo do Controller.

A segunda refere-se à dificuldade de garantir a plena compreensão das questões pelos entrevistados, ainda que a estratégia de entrevista possibilite reduzir significativamente essa limitação. Por fim, apesar dos benefícios de um estudo em profundidade, tem-se de outra parte a impossibilidade de generalização dos resultados pois a pesquisa é um único caso e reflete a realidade da empresa pesquisada. Tal limitação foi amenizada pela comparação com outros estudos realizados com amostra de maior amplitude. 


\section{APRESENTAÇÃO E ANÁLISE DOS DADOS}

\subsection{USO DE PRÁTICAS DE CONTABILIDADE GERENCIAL}

\subsubsection{Práticas Tradicionais de CG}

Nesta parte são apresentados os dados relativos à quantificação das escalas representativas do uso das práticas tradicionais de CG, conforme consta da Tabela 1.

Tabela 1 - Utilização de Práticas Tradicionais de CG

\begin{tabular}{l|c|c|c|c|c|c}
\hline Práticas Tradicionais de CG & $\mathbf{1}$ & $\mathbf{2}$ & $\mathbf{3}$ & $\mathbf{4}$ & $\mathbf{5}$ & $\mathbf{R M}$ \\
\hline Análise da Relação CVL & 3 & 1 & 1 & 2 & 0 & 2,3 \\
Custo Padrão & 0 & 1 & 0 & 1 & 5 & 4,4 \\
Orçamento Anual & 0 & 0 & 0 & 1 & 6 & 4,9 \\
Planejamento Estratégico & 1 & 0 & 0 & 1 & 5 & 4,3 \\
Medidas de Retorno & 2 & 0 & 2 & 2 & 1 & 3,0 \\
Análise de Lucratividade & 2 & 0 & 1 & 0 & 4 & 3,6 \\
Análise Econ. de Investimentos & 3 & 0 & 1 & 2 & 1 & 2,7 \\
Resultado por área de negócio & 0 & 0 & 1 & 4 & 2 & 4,1 \\
Precificação de Produtos & 3 & 0 & 0 & 2 & 2 & 3,0 \\
\hline \multicolumn{1}{c|}{ RM - Global } & $\mathbf{1 4}$ & $\mathbf{2}$ & $\mathbf{6}$ & $\mathbf{1 5}$ & $\mathbf{2 6}$ & $\mathbf{3}$ \\
\hline
\end{tabular}

Fonte: Dados da pesquisa.

As práticas constantes da Tabela 1 destacam-se como as mais frequentemente citadas em estudos relacionados à contabilidade gerencial. Uma prática muito citada é a análise da relação CVL e práticas decorrentes (Ponto de Equilíbrio, MSO e GAO) e, contrariando a ênfase da literatura (GARRISON; NOREEN; BREWER, 2013; BLOCHER et al. 2007), a pesquisa indica ser ela a menos utilizada na empresa pesquisada, com RM de apenas 2,3.

Três outras práticas, também bastante exploradas na literatura, são: o custo-padrão (GARRISON; NOREEN; BREWER, 2013; MARIE et al. 2010), o orçamento anual (KHAN; KHALIQUE, 2014; TEMTIME, 2003), e o planejamento estratégico (KHAN; KHALIQUE, 2014; TEMTIME, 2003) que encontram alta recepção pela empresa, todas elas com elevados RM. Com RM muito próximo a essas últimas $(4,1)$ a mensuração do resultado por área de negócio também se mostra relevante, corroborando a abordagem dada por Assaf (2012) e Bhimani et al. (2015). As demais práticas encontram-se em faixa intermediária de aplicação, o que corrobora, pelo menos em parte, a aderência da empresa em relação ao que apregoa a literatura em relação às práticas tradicionais de CG.

Estudos empíricos relacionados (DUGDALE; JONES; GREEN, 2006) corroboram os resultados encontrados neste estudo, particularmente com relação ao custo padrão, orçamento e margem de contribuição, esta última relacionada à análise CVL. Também os resultados do estudo de Souza e Gasparetto (2017) são agora confirmados, principalmente às práticas de análise CVL (os autores referem-se ao breakeven point - ponto de equilíbrio e orçamento). Quanto ao custo-padrão, a segunda prática mais citada pelos respondentes, também vem ao encontro do resultado identificado no estudo de Muniz (2010). A utilização do orçamento e análise CVL também são destacadas como citadas com alta intensidade no estudo de Abdel-Kader e Luther (2006).

\subsubsection{Práticas Contemporâneas de CG}

A apresentação das escalas representativas do uso das práticas contemporâneas de CG consta da Tabela 2. Da mesma forma que as práticas tradicionais, as contemporâneas também foram quantificadas no RM correspondente. 
Tabela 2 - Utilização das Práticas Contemporâneas de CG

\begin{tabular}{l|c|c|c|c|c|c}
\hline Práticas Contemporâneas de CG & $\mathbf{1}$ & $\mathbf{2}$ & $\mathbf{3}$ & $\mathbf{4}$ & $\mathbf{5}$ & $\mathbf{R M}$ \\
\hline Análise dos Fatores Determinantes de Custos & 3 & 0 & 0 & 2 & 2 & 3,0 \\
Análise e Custeio ABC e TDABC & 3 & 1 & 2 & 1 & 0 & 2,1 \\
Análise da gestão ABM & 5 & 0 & 1 & 1 & 0 & 1,7 \\
Análise do custo de Qualidade e custos Ambientais & 2 & 0 & 4 & 1 & 0 & 2,6 \\
Análise de Desempenho dos Concorrentes & 5 & 0 & 0 & 1 & 1 & 2,0 \\
Análise de Desempenho dos clientes & 4 & 0 & 1 & 2 & 0 & 2,1 \\
Custo Meta & 2 & 0 & 1 & 3 & 1 & 3,1 \\
Custos Logísticos & 1 & 0 & 2 & 2 & 2 & 3,6 \\
\hline RM - Global & $\mathbf{2 5}$ & $\mathbf{1}$ & $\mathbf{1 1}$ & $\mathbf{1 3}$ & $\mathbf{6}$ & $\mathbf{2}$ \\
\hline
\end{tabular}

Fonte: Dados da pesquisa.

Comparativamente ao uso às práticas tradicionais, apresentadas na Tabela 1 , verifica-se que nessas práticas contemporâneas a intensidade de uso é bem inferior. Neste grupo, nenhuma prática aproximou-se de forma acentuada à escala 4, presente em quatro das práticas anteriores. Também, enquanto nas práticas tradicionais, o menor RM foi de 2,3 (análise da relação CVL), nas contemporâneas tem-se quatro práticas com escalas inferiores a essa.

Da mesma forma como ocorre em relação as práticas tradicionais, também nas contemporâneas tem-se uma literatura com posicionamentos amplamente favoráveis à sua utilização pelas empresas. Enquanto Carneiro (2015), Pivru et al. (2012) e Shank (1989) argumentam a favor da utilidade da análise dos fatores determinantes de custos, Camacho e Rocha (2008), Swenson et al. (2003) e Sakurai (1997) enfatizam favoravelmente a utilização do custo-meta. A utilidade de mensuração e análise dos custos logísticos também contam com literatura favorável à sua adoção (FARIA; COSTA, 2012; ZHAO; TANG, 2009; ZENG; ROSSETI, 2003). Por fim, para se concentrar apenas nas práticas mais citadas pelos respondentes, tem-se a análise dos custos da qualidade e custos ambientais, amplamente discutida de forma positiva por diversos estudiosos (BLOCHER et al. 2007; JEFFREY, 2002; HANSEN; MOWEN, 2001; KOCSIS; BEM, 2012, KEITEL, 2011).

Apesar dessa ênfase favorável à adoção de práticas contemporâneas dadas pela literatura, o que se verifica é a sua adoção a níveis sensivelmente inferiores às tradicionais. Tem-se, então, uma dissociação ou afastamento significativo entre o que recomenda a literatura e aquilo que é recepcionado pela prática empresarial.

De fato, como já indicado, estudos empíricos relacionados (YAP et al., 2013) dão destaque à pouca adesão dada pelas empresas à utilização das novas recomendações pela literatura, o que é corroborado pelos resultados desta pesquisa (YAP et al., 2013; AHMAD, 2014; LEITE; FERNANDES; LEITE, 2015; OGUNGBADE, 2016). Pesquisas nacionais também vão ao encontro dos resultados desta pesquisa, realçando a baixa adesão às práticas contemporâneas (SOUZA; LISBOA; ROCHA, 2003; RECKZIEGEL; SOUZA; DIEHL, 2007; TEIXEIRA et. al., 2011; RUSSO; GUERREIRO, $2017 b)$.

Dois outros estudos mostram maior equilíbrio do uso de práticas contemporâneas, apesar de não ser com a dimensão majoritária. Na verdade, esses estudos revelam aplicação mais equilibrada entre as duas classes de práticas. Isso é particularmente encontrado no estudo de Souza, Fontana e Boff (2010), no qual há citação do uso do custo-meta em paralelo à utilização do custo-padrão, uma prática tradicional. O mesmo se encontra no estudo de Andrade et al. (2013), onde o custo-meta é novamente citado, comparativamente a práticas de custeio e formação de preços. Assim, ainda que contrário aos achados em geral pela presente pesquisa, há nesses estudos maior proximidade com a literatura que enfatiza o uso de práticas contemporâneas. Mas, mesmo nesse caso, esses dois estudos não evidenciam adoção majoritária dessas práticas mais atuais, o que não deixa de ser um parcial desencontro com a literatura mais enfática quanto aos benefícios diferenciados pelo uso dessas práticas mais recentes.

\subsection{PERCEPÇÕES QUANTO AO USO DE PRÁTICAS DE CG}

\subsubsection{Grau de Beneficio Percebido}

A segunda questão da pesquisa é destinada a identificar a percepção dos usuários em relação ao grau de benefício que há pela utilização das práticas de CG na gestão. O benefício com as práticas tradicionais está apresentado na Tabela 3. 
Tabela 3 - Grau do Benefício com o Uso das Práticas Tradicionais de CG

\begin{tabular}{l|l|l|l|l|l|c}
\hline Práticas Tradicionais de CG & $\mathbf{1}$ & $\mathbf{2}$ & $\mathbf{3}$ & $\mathbf{4}$ & $\mathbf{5}$ & $\mathbf{R M}$ \\
\hline Análise da Relação CVL & 2 & 2 & 0 & 3 & 0 & 2,6 \\
Custo Padrão & 0 & 0 & 1 & 1 & 5 & 4,6 \\
Orçamento Anual & 0 & 0 & 0 & 2 & 5 & 4,7 \\
Planejamento Estratégico & 0 & 0 & 1 & 2 & 4 & 4,4 \\
Medidas de Retorno & 2 & 1 & 1 & 2 & 1 & 2,9 \\
Análise de Lucratividade & 2 & 0 & 0 & 1 & 4 & 3,7 \\
Análise Econômica de Investimentos & 3 & 0 & 1 & 2 & 1 & 2,7 \\
Análise de resultado por área de negócio & 1 & 1 & 0 & 2 & 3 & 3,7 \\
Precificação de Produtos & 3 & 0 & 0 & 1 & 3 & 3,1 \\
\hline RM - Global & $\mathbf{1 3}$ & $\mathbf{4}$ & $\mathbf{4}$ & $\mathbf{1 6}$ & $\mathbf{2 6}$ & $\mathbf{3}$ \\
\hline
\end{tabular}

Fonte: Dados da pesquisa.

De forma análoga ao conteúdo da Tabela 1, o reconhecimento do benefício com o uso de práticas tradicionais de CG centra-se principalmente no custo-padrão, orçamento anual, planejamento estratégico, análise de lucratividade e análise de resultado por área de negócio. Apesar dos pequenos desvios entre o RM dessas práticas tradicionais, observa-se que esse conjunto de indicadores, quando consolidado, manteve o mesmo nível de 3,6 em ambos os tópicos analisados (adoção x grau de benefício). Essa é uma sinalização da consistência no posicionamento dos respondentes.

De fato, também quanto aos benefícios tem-se o maior reconhecimento preferencial quanto ao custo-padrão, orçamento e planejamento operacional e análise CVL. Diferença maior, apesar de consistente no conjunto, é o menor benefício atribuído à prática de análise de resultado por área de negócio. Em relação ao custo-padrão os elevados resultados corroboram a pesquisa de Rasia (2011).

Mesma situação se verifica na média global das práticas tradicionais, mantidas em exatos 3,6 tanto na escala de uso, quanto na de benefício pelo uso. Os resultados relacionados às práticas contemporâneas encontram-se na Tabela 4.

Tabela 4 - Grau do Benefício com o Uso das Práticas Contemporâneas de CG

\begin{tabular}{l|c|c|c|c|c|c}
\hline Práticas Contemporâneas de CG & $\mathbf{1}$ & $\mathbf{2}$ & $\mathbf{3}$ & $\mathbf{4}$ & $\mathbf{5}$ & $\mathbf{R M}$ \\
\hline Análise dos Fatores Determinantes de Custos & 3 & 0 & 0 & 2 & 2 & 3,0 \\
Análise e Custeio ABC e TDABC & 3 & 2 & 1 & 1 & 0 & 2,0 \\
Análise da gestão ABM & 5 & 0 & 0 & 2 & 0 & 1,9 \\
Análise do custo de Qualidade e custos Ambientais & 2 & 1 & 3 & 0 & 1 & 2,6 \\
Análise de Desempenho dos Concorrentes & 5 & 0 & 0 & 0 & 2 & 2,1 \\
Análise de Desempenho dos clientes & 4 & 1 & 0 & 0 & 2 & 2,3 \\
Custo Meta & 2 & 0 & 1 & 3 & 1 & 3,1 \\
Custos Logísticos & 0 & 2 & 1 & 2 & 2 & 3,6 \\
\hline RM - Global & $\mathbf{2 4}$ & $\mathbf{6}$ & $\mathbf{6}$ & $\mathbf{1 0}$ & $\mathbf{1 0}$ & $\mathbf{2}, \mathbf{6}$ \\
\hline
\end{tabular}

Fonte: Dados da pesquisa.

Nesse grupo de práticas contemporâneas de CG encontra-se a mesma situação de consistência apresentada no grupo das práticas tradicionais. Na escala média global, por exemplo, o uso foi mensurado em 2,5 contra 2,6 nos benefícios. E ambos refletem a baixa utilização dessas práticas e baixo reconhecimento dos benefícios provocados pelo seu uso,

A consistência global destacada também se verifica isoladamente entre as práticas, especificamente naquelas mais indicadas (custos logísticos, custo-meta e determinantes de custos). Portanto, também menor em relação aos benefícios indicados para as práticas tradicionais.

Apesar de não ser objetivo deste estudo identificar fatores causadores do uso ou não das práticas analisadas, faz-se aqui, por analogia, possíveis identificações para o não uso das práticas contemporâneas, como identificado neste estudo. Assim, os resultados do estudo de Albu e Albu (2012), realizado com empresas industriais da Romênia, faz menção ob- 
jetiva quanto à irrelevância estatística de um ambiente de alta competição como um fator indutor à adoção das práticas contemporâneas, indo de encontro a argumentos da literatura (TURNEY; ANDERSON, 1989; PEAVEY, 1998).

Os resultados desta pesquisa, em desacordo com a literatura, segundo esclarecem Albu e Albu (2012), corroboram os achados de pesquisas realizadas em países mais desenvolvidos, dando-lhe um aspecto de validação. Nesse mesmo estudo há indicações de que em empresas com capital estrangeiro (multinacionais) foi encontrada relação positiva em favor da utilização das práticas contemporâneas. Isso já não é confirmado por esta pesquisa, pois que, apesar de realizada com uma empresa de origem alemã (multinacional) não se constata uso relevante desse tipo de práticas, conforme dados da Tabela 2. Isso também está presente na pesquisa de Souza, Lisboa e Rocha (2003), os quais pesquisaram o tema com subsidiárias brasileiras de empresas multinacionais de diversos países.

O estudo de Ahmad (2014), realizado com indústrias da Líbia, também identificou muito baixo uso de práticas contemporâneas. $\mathrm{Na}$ análise dos dados o autor também enfatiza que esse resultado da pesquisa corrobora outros realizados em países desenvolvidos. Nos fatores que justificam a baixa adesão, Ahmad (2014) lista os seguintes: (1) falta de uma sociedade de profissionais em contabilidade gerencial no país; (2) falta de programas de treinamento e cursos acadêmicos que tratem dessas práticas; (3) falta de softwares com tecnologia que viabilizem essa utilização; (4) falta de publicações de qualidade sobre tais práticas. Acha-se aqui uma aparente falta de consistência, dado que a ausência desses fatores não se mostra em países desenvolvidos e isso não conduziu a maior nível de aplicação de práticas contemporâneas como está implícito na igualdade de pesquisas com esse objetivo. Tem-se, então, que as causas de não uso devem ser outras até então não investigadas, revelando-se aí novos campos para pesquisa específica sobre o tema.

\subsubsection{Grau de Dificuldade Percebida}

O terceiro grupo de assertivas identifica a dificuldade percebida pelos respondentes na utilização das práticas tradicionais e contemporâneas de CG. Neste caso, quanto maior a escala pior é a situação apresentada, contrariamente ao que se teve nas análises e tabelas anteriores. Os dados da Tabela 5 mostra tal situação.

Tabela 5 - Grau de Dificuldade no Uso de Práticas Tradicionais de CG

\begin{tabular}{l|c|c|c|c|c|c}
\hline Práticas Tradicionais de CG & $\mathbf{1}$ & $\mathbf{2}$ & $\mathbf{3}$ & $\mathbf{4}$ & $\mathbf{5}$ & $\mathbf{R M}$ \\
\hline Análise da Relação CVL & 0 & 3 & 1 & 0 & 3 & 3,4 \\
Custo Padrão & 1 & 5 & 1 & 0 & 0 & 2,0 \\
Orçamento Anual & 1 & 4 & 2 & 0 & 0 & 2,1 \\
Orçamento Estratégico & 1 & 3 & 1 & 1 & 1 & 2,7 \\
Medidas de Retorno & 1 & 1 & 2 & 1 & 2 & 3,3 \\
Análise de Lucratividade & 1 & 2 & 2 & 0 & 2 & 3,0 \\
Análise Econômica de Investimentos & 2 & 1 & 2 & 2 & 0 & 2,9 \\
Análise de resultado por área de negócio & 1 & 1 & 3 & 1 & 1 & 3,0 \\
Precificação de Produtos & 0 & 0 & 2 & 1 & 4 & 4,3 \\
\hline RM - Global & $\mathbf{8}$ & $\mathbf{2 0}$ & $\mathbf{1 6}$ & $\mathbf{6}$ & $\mathbf{1 3}$ & $\mathbf{3}, \mathbf{0}$ \\
\hline
\end{tabular}

Fonte: Dados da pesquisa.

A exemplo do que foi identificado na análise dos benefícios percebidos pelo uso, em relação às respectivas escalas, também aqui há consistência entre os resultados da pesquisa, ou seja, a análise das dificuldades no uso mostra relação inversa com as dos benefícios. Análise comparativa entre os dados das Tabelas 3 e 6 evidencia que as práticas de maior dificuldade de uso são aquelas de menor benefício e de menor uso.

Os dados da Tabela 5 mostra que as práticas de precificação de produtos, de análise CVL e de medidas de retorno foram citadas como as de maior dificuldade, de menor benefício e de menor utilização. Interessante notar que a intensidade da escala global de benefício $(3,6)$ é maior do que a de dificuldade $(3,0)$, indicando maior proporção geral dos benefícios em relação às dificuldades. Ou seja, a relação benefício versus dificuldades é favorável em cerca de 20\%. (Tabela 6). Tais achados corroboram a pesquisa de Rasia (2011), com relação à prática de análise dos fatores determinantes de custos. 
Tabela 6 - Grau de Dificuldade no Uso de Práticas Contemporâneas de CG

\begin{tabular}{l|l|l|l|l|c|c}
\hline Práticas Contemporâneas de CG & $\mathbf{1}$ & $\mathbf{2}$ & $\mathbf{3}$ & $\mathbf{4}$ & $\mathbf{5}$ & $\mathbf{R M}$ \\
\hline Análise dos Fatores Determinantes de Custos & 1 & 2 & 1 & 0 & 3 & 3,3 \\
Análise e Custeio ABC e TDABC & 1 & 1 & 0 & 1 & 4 & 3,9 \\
Análise da gestão ABM & 0 & 1 & 0 & 1 & 5 & 4,4 \\
Análise custo Qualidade e Ambientais & 1 & 1 & 3 & 1 & 1 & 3,0 \\
Análise de Desempenho dos Concorrentes & 0 & 0 & 0 & 2 & 5 & 4,7 \\
Análise de Desempenho dos clientes & 0 & 1 & 2 & 0 & 4 & 4,0 \\
Custo Meta & 0 & 3 & 2 & 0 & 2 & 3,1 \\
Custos Logísticos & 0 & 1 & 3 & 3 & 0 & 3,3 \\
\hline RM - Global & $\mathbf{3}$ & $\mathbf{1 0}$ & $\mathbf{1 1}$ & $\mathbf{8}$ & $\mathbf{2 4}$ & $\mathbf{3}, \mathbf{7}$ \\
\hline
\end{tabular}

Fonte: Dados da pesquisa.

Observa-se que, nas práticas contemporâneas há mesma consistência verificada nas tradicionais. De fato, nota-se que as práticas citadas com baixo uso e baixo benefício no uso mostram agora elevado indicador de dificuldade no uso. Isso ocorre particularmente com as práticas de análise de desempenho de clientes, de fornecedores e do uso das atividades como instrumento de mensuração e gestão (ABC e ABM).

\subsubsection{Relação de Correspondência entre Uso, Beneficio e Dificuldade}

Após esses primeiros três grupos de análise (uso, benefício e dificuldade) em relação às práticas de CG, é possível identificar o grau de correspondência entre elas (Tabela 7), um resumo dos conteúdos das Tabelas 1 a 6.

Tabela 7 - Grau de Correspondência (RM) das Análises Uso, Benefício e Dificuldade

\begin{tabular}{c|c|c|c}
\hline Classe de Práticas & Uso & Beneficio & Dificuldade \\
\hline Tradicionais & 3,6 & 3,6 & 3,0 \\
Contemporâneas & 2,5 & 2,6 & 3,7 \\
\hline
\end{tabular}

Fonte: Dados da pesquisa.

Verifica-se que, quanto maior o uso, equivalente proporção tem-se na expressão dos benefícios, e relação inversa no que se refere ao RM das dificuldades. Assim, as práticas tradicionais, com maior uso e benefício, apresentam proporcionalmente menor grau de dificuldade. Já quanto as práticas contemporâneas, menor é o RM de uso e benefício e, em contrapartida, maior é o RM do grau de dificuldade.

Esses dados possibilitam inferir que a falta de identificação objetiva quanto aos benefícios do uso das práticas acaba por restringir a sua maior aplicação. O elemento "Dificuldade" pode aqui ser traduzido como um desinteresse decorrente. Parece lógico deduzir que se o benefício é mais reconhecido, esforços adicionais (inclusive de investimentos em pessoal e sistemas) seriam dedicados a melhor estruturar o uso das práticas como enfatiza a teoria já citada nas etapas anteriores desta análise. Em resumo, parece que os argumentos teóricos não foram ainda suficientes para convencer os gestores sobre os benefícios de uma relação custo $\mathrm{x}$ benefício possivelmente mais favorável.

\subsection{RELAÇÕES ENTRE PRÁTICAS DE CG E TIPO DE DECISÃO}

Esta última parte da apresentação e análise dos dados trata de relacionar os tipos de decisões com as respectivas práticas de CG utilizadas. Para medir esta relação os respondentes indicaram, pela ordem, as três práticas mais utilizadas para cada decisão. Os Dados são apresentados no Quadro 6. 
Quadro 6 - Relação Entre o Tipo de Decisão e Práticas de CG Utilizadas

\begin{tabular}{|c|c|c|c|}
\hline Tipo de Decisão & $1^{a}$. Prática & $2^{a}$. Prática & $3^{\mathrm{a}}$. Prática \\
\hline $\begin{array}{l}\text { Aumento da margem de } \\
\text { contribuição }\end{array}$ & Determinantes de Custos & Custo Meta & $\begin{array}{c}\text { Análise de } \\
\text { Desempenho Clientes }\end{array}$ \\
\hline $\begin{array}{l}\text { Identificar e eliminar atividades } \\
\text { sem valor }\end{array}$ & Custo Padrão (tradicional) & Custo Meta & $\begin{array}{l}\text { Análise de custo de processo } \\
\text { (Setup) }\end{array}$ \\
\hline $\begin{array}{c}\text { Adoção de ações que diminuam } \\
\text { a ineficiência }\end{array}$ & $\begin{array}{l}\text { Análise de custo de processo } \\
\text { (Setup) }\end{array}$ & Custo Logístico & Custo padrão \\
\hline $\begin{array}{l}\text { Redução ou eliminação de } \\
\text { custos fixos }\end{array}$ & Orçamento anual (tradicional) & $\begin{array}{l}\text { Análise econômica de } \\
\text { Investimentos }\end{array}$ & Custo Padrão \\
\hline $\begin{array}{c}\text { Ações voltadas a análise de } \\
\text { investimentos }\end{array}$ & $\begin{array}{c}\text { Análise econômica de } \\
\text { Investimentos (tradicional) }\end{array}$ & Custo Padrão & Orçamento Anual \\
\hline $\begin{array}{l}\text { Decisões de compra de } \\
\text { materiais }\end{array}$ & Custo Padrão (tradicional) & $\begin{array}{l}\text { Análise econômica de } \\
\text { Investimentos }\end{array}$ & Custo logístico \\
\hline Controlar o tempo de execução & $\begin{array}{l}\text { Análise de custo de processo } \\
\text { (Setup) }\end{array}$ & Custo Meta & Orçamento Anual \\
\hline $\begin{array}{l}\text { Lançamento e Eliminação de } \\
\text { produtos }\end{array}$ & Custo Meta & $\begin{array}{l}\text { Análise da relação custo- } \\
\text { volume-lucro }\end{array}$ & $\begin{array}{l}\text { Análise de desempenho dos } \\
\text { concorrentes }\end{array}$ \\
\hline Agilizar o processo de produção & $\begin{array}{l}\text { Análise de custo de processo } \\
\text { (Setup) }\end{array}$ & $\begin{array}{l}\text { Análise econômica de } \\
\text { Investimentos }\end{array}$ & Custo Meta \\
\hline Analisar o custo logístico & Custo Logístico & Orçamento Anual & Custo Padrão \\
\hline Planejar e controlar os custos & Orçamento Anual (tradicional) & Custo Padrão & Custo Meta \\
\hline Aumento da competitividade & Custo Meta & Determinantes de Custos & Orçamento Anual \\
\hline
\end{tabular}

Fonte: Dados da Pesquisa.

Observa-se, no conjunto das três opções, a igualdade de vezes (sete) de citação entre custo-meta e custo-padrão. Após tem-se o orçamento com seis vezes. Como terceira prática mais citada há outro empate (quatro vezes) entre análise econômica de investimentos e análise de custos de setup. Quanto ao equilíbrio do uso entre custo-meta e custo-padrão, apesar disso ir de encontro ao que preceitua os desenvolvimentos teóricos, que privilegiam o uso do custo-meta (CAMACHO; ROCHA, 2008; SWENSON et al. 2003; SAKURAI, 1997), corrobora estudos empíricos precedentes (SOUZA; FONTANA; BOFF, 2010; ANDADE et al., 2013; ANGELIAKIS; THERIOU; FLOROPOULO, 2010).

O uso do orçamento também se mostra com semelhante quantidade de citações que o custo-padrão. Esse resultado também indica contradição em relação à literatura mais recente que apregoa o uso de uma nova modalidade de orçamentos intitulada beyond budget (FREZATTI, 2005). Outras práticas antes não citadas com destaque surgem agora com maior preferência (análise econômica de investimentos e análise de custos de setup). Isso é importante pois revela que, para utilização mais específica, é possível encontrar-se informação diferente daquela do uso em geral.

A partir do Quadro 6 elaborou-se a Tabela 8, a qual resume, de forma quantitativa, a prática utilizada em relação à decisão apresentada. Essa tabela resumo facilita a visão geral das práticas mais utilizadas na respectiva ordem de preferência dada pelos respondentes.

Tabela 8 - Resumo das Preferências por Categorias de Práticas de CG

\begin{tabular}{c|c|c|c|c}
\hline Categorias de Práticas de CG & $\mathbf{1}^{\mathbf{a}}$ Opção & $\mathbf{2}^{\mathbf{a}}$ Opção & 3 $^{\mathbf{a}}$ Opção & Total \\
\hline Tradicional & 5 & 7 & 6 & 18 \\
Contemporânea & 7 & 5 & 6 & 18 \\
Total & 12 & 12 & 12 & 36 \\
\hline
\end{tabular}

Fonte: Dados da pesquisa. 
Constata-se que, como primeira opção, tem-se leve predominância das práticas contemporâneas (sete contra cinco). Já como segunda opção tem-se uma inversão de ordem, agora com a maior indicação das tradicionais (sete contra 5). E como terceira opção há total equilíbrio entre elas (seis contra seis). Ao final mostra-se total equilíbrio entre as práticas quando consideradas as três opções em conjunto. Observa-se que quando analisado em função de decisões específicas não há diferença relevante na preferência de um ou outro grupo de práticas (tradicionais ou contemporâneas).

Após a apresentação e análise geral e individual de cada foco de uso específico das práticas tradicionais e contemporâneas, observa-se que mudanças pontuais podem ocorrer na ordem de preferência, apesar da maior citação das práticas tradicionais em geral. Esses achados, quando analisados comparativamente a literatura que argumenta de forma favorável à adoção das práticas contemporâneas, mostra divergência já que essa preferência não é constatada. Destaque deve ser dado à ênfase dada ao custo-meta, mesmo que adotada de forma concomitante ao custo-padrão. Com relação aos estudos anteriores, constata-se elevada consistência de resultados, ou seja, há maior concentração geral ao uso das práticas tradicionais, apesar da presença de práticas contemporâneas em decisões mais pontuais.

\section{CONCLUSÃO}

O objetivo deste estudo foi investigar a adoção de práticas de contabilidade gerencial (CG) na gestão de uma empresa industrial gaúcha de grande porte. Essa investigação compreende inclusive a identificação dessas práticas em relação a decisões especificas, além das dificuldades e benefícios esperados pelo seu uso. Para melhorar a apresentação e análise as práticas foram separadas em dois grupos, ou seja, as consideradas tradicionais e aquelas tratadas como contemporâneas pela literatura que aborda o tema.

Os principais achados ratificam aqueles encontrados em outros estudos empíricos, os quais mostram que o uso das práticas tradicionais ainda se apresenta de forma elevada, uma parcial discordância com relação aos desenvolvimentos teóricos mais recentes. Apesar de não ser parte do objetivo do estudo, observou-se o impacto desfavorável às práticas contemporâneas dado pela falta de maior objetividade na relação custo x benefício e nas dificuldades de implantação, provocadas por falta de um sistema de informações adequado, dificuldade em compreender as efetivas contribuições que as novas práticas iriam acrescentar. A comparação dos resultados com estudos antecedentes permite que, por analogia, se tenha esse entendimento (YAP et al. 2013).

Outra suposição passível de ser apresentada é que a falta de um treinamento mais efetivo e sistematizado de gestores e profissionais da área de custos e controladoria, incluindo-se aí simulações de aplicação prática a decisões específicas pode provocar menor clareza no entendimento dos possíveis benefícios das práticas contemporâneas (YAP et al. 2013; OGUNGBADE, 2016).

Quanto à possibilidade de novas pesquisas, algumas foram identificadas até mesmo para superar parte das limitações deste estudo. Nesse sentido, sugere-se duas pesquisa específicas: (1) verificar, de forma objetiva, o porquê da baixa utilização das práticas contemporâneas de CG, ou seja, quais motivos conduzem à permanência com práticas tradicionais apesar do enfoque contrário dado pela literatura. Para essa sugestão, estudos de caso em profundidade parece ser a estratégica metodológica mais apropriada. Tal pesquisa pode fornecer parâmetros para uma pesquisa do tipo survey que permita inferências ou mesmo generalizações com maior segurança e abrangência; (2) investigar a possibilidade de que determinados setores da economia, como o industrial e/ou de serviços por exemplo, demandariam ferramentas gerenciais especificamente a eles apropriados - analisar pesquisas já realizadas sob a temática pode ser um adequado início para esclarecimento dessa indagação.

\section{REFERÊNCIAS}

Abdel-Kader, M.; LUTHER, R. Management accounting practices in the British food and drinks industry. British Food Journal, v. 108 , n. 5, p. 336-357, 2006.

ABDEL-MAKSOUD, A. B. Management accounting practices and managerial techniques and practices in manufacturing firms: Egyptian evidence. International Journal Managerial and Financial Accounting, v. 3, n. 3, p. 237-254, 2011.

Ahmad, N. S. M.; leftsi, a. An exploratory study of the level of sophistication of management accounting practices in Libyan manufacturing companies. International Journal of Business and Management, v. 2, n. 2, p. 1-10, 2014.

Albu, N.; Albu, C. N. Factors associated with the adoption and use of management accounting techniques in developing countries: the case of Romania. The Journal of International Financial Management \& Accounting, v. 23, n. 3, p. 245-276, 2012.

ANDERSON, S.; GUILDING, C. Competitor focused accounting applied to a hotel contexto. International Journal of Contemporary Hospitality Management, v. 18, n. 3, p. 206-218, 2006.

ANDRADE, L. C. M.; TEIXEIRA, A. J. C; FORTUNATO, G.; NOSSA, V. Determinantes para a utilização de práticas de contabilidade gerencial estratégica: um estudo empírico. Revista de Administração Mackenzie, v. 14, n. 1, p. 98-125, 2013.

ANGELAKIS, G.; THERIOU, N.; FLOROPOULOS, I. Adoption and benefits of management accounting practices: evidence from Greece and Finland. Advances in Accounting, v. 26, n. 1, p. 87-96, 2010.

ASSAF NETO, A. Finanças corporativas e valor. 6. ed. São Paulo: Atlas, 2012. 
ATKINSON, A. A.; BANKER, R. D.; KAPLAN, R. S.; YOUNG, S. M. Contabilidade gerencial. São Paulo: Atlas, 2000.

Bangara, S. N. Contextual factors influencing management accounting practices adopted by large manufacturing companies in Kenya. Research Journal of Finance and Accounting, v. 8, n. 23, p. 7-19, 2017.

BARLEY, S. R.; Tolbert, P. S. Institutionalization and structuration: studying the links between action and institution. Organization Studies, v. 18, n. 1, p. 93-117, 1997.

Bhimani A, Horngren C. T, Datar S. M, Rajan M. Management and cost accounting, 6 ed. New York, Pearson, 2015.

BLOCHER, E. J.; CHEN, K. H.; COKINS, G.; LIN, T. W. Gestão estratégica de custos. São Paulo, McGraw-Hill, 2007.

BRIMSON, J. A. Contabilidade por atividades: uma abordagem de custeio baseado em atividades. São Paulo, Atlas, 1996.

Burns, J.; Scapens, R. W. Conceptualizing management accounting change: an institutional framework. Management Accounting Research, v. 11, n. 1, p. 3-25, 2000.

CAMACHO, R. R.; ROCHA, W. Custeio Alvo em serviços hospitalares: um estudo sob o enfoque da gestão estratégica de custos. Revista Contabilidade \& Finanças, v. 19, n. 47, p. 19-30, 2008.

CARNEIRO, d. m. Determinantes de custos: uma proposta de sistematização. Dissertação (Mestrado em Controladoria e Contabilidade), Universidade de São Paulo. São Paulo, SP, Brasil, 2015.

CERVO, A. L.; BERVIAN, P. A.; SILVA, R. Metodologia científica. São Paulo: Pearson, 2007.

COASE R. H. The nature of the firm. Economica, v. 4, n. 16, p. 386-405. 1937

COOPER, R.; SLAGMULDER, R. Strategic Cost Management: expanding scope and boundaries. Cost Management, v. 17, n. 1, p. 23-30, 2003.

COOPER, R.; SLAGMULDER, R. Cost analysis outside the organization. Cost Management, v. 18, n. 3, p. 44-46, 2004.

Dugdale, D.; Jones, T. C.; Green, S. Contemporary management accounting practice in UK manufacturing. Oxford, CIMA Publishing \& Elsevier, (2006).

FARIA, A. C.; COSTA, M. F. G. Gestão de custos logísticos. São Paulo: Atlas, 2012.

FILIPINI, F.; BORTULOZZI, C. A. P.; CAMARGO, T. F.; PIEKAS, A. A. S.; MANFROI, L. A utilidade da informação contábil no processo de tomada de decisão: um estudo da percepção dos gestores das empresas de médio porte localizadas em Chapecó - SC. In: CONGRESSO DE CONTABILIDADE DA UFRGS, 3. Porto Alegre, UFRGS, 2018. Anais [...] Porto Alegre: UFGRS, 2018.

FOSTER, G.; GUPTA, M.; SJOBLOM, L. Costumer profitability analysis: challenges and new directions. Journal of Cost Management, v. 10, n. 1, p. 1-14, 1997.

FREZATTI, F. Beyond budgeting: inovação ou resgate de antigos conceitos do orçamento empresarial? Revista RAE, v. 45, n. 2, p. 23-33, 2005 .

GARRISON, R.H.; NOREEN, E. W.; BREWER, P. C. Contabilidade gerencial. 14. ed. Porto Alegre, AMGH, 2013.

GHAHREMANI, M. AGHAIE, A.; ABEDZADEH, M. Capital budgeting technique selection through four decades with a great focus on real option. International Journal of Business and Management, v. 7, n. 17, p. 09-119, 2012.

GOMES, J. S. Tópicos contemporâneos em contabilidade - chamada para pesquisas. Revista Brasileira de Contabilidade, $\mathrm{n}$. 91, p. 79, 1995.

Guerreiro, R.; Frezatti, F.; Lopes, A. B.; Pereira, C. A. O entendimento da contabilidade gerencial sob a ótica da teoria institucional. Organizações \& Sociedade, v. 12, n. 35, p. 91-106, 2005.

HAIR JÚNIOR, F.; BABIN, B. J.; MONEY, A. H.; SAMOUEL, P. Fundamentos de métodos de pesquisa em administração. Porto Alegre: Bookman, 2005.

HANSEN, D. R.; MOWEN, M. M. Gestão de custos. São Paulo, Thomson Learning, 2001.

HARMON, R. L. Reinventando a fábrica: conceitos modernos de produtividade aplicados na prática. Rio de Janeiro: Campus, 1991.

HOFFJAN, A.; HEINEN, C. The strategic relevance of competitor cost assessment: an empirical study of competitor accounting. Journal of Applied Management Accounting Research, v. 3, n. 1, p. 17-33, 2005.

HOJI, M. Administração financeira e orçamentária. 11. ed. São Paulo: Atlas, 2014.

International Federation of Accountants (IFAC). International management accounting practice statement: management accounting concepts. New York, 1998.

IUDÍCIBUS, S. A gestão estratégica de custos e sua interface com a contabilidade gerencial e teoria da contabilidade: uma análise sucinta. Revista Brasileira de Contabilidade, v. 100, p. 30-31, 1996.

JEFFREY, A. B. Managing quality: modeling the cost of quality improvement. Southwest Business and Economics Journal, v. 12, n. 2003/2004, p. 25-36, 2004.

JOHSON, H. t.; KAPLAN, R. S. Relevance lost. Boston, Harvard Business School Press, 1987.

KAPLAN, R. S.; ANDERSON, S. R. Time-driven ABC costing. Boston: HBSP, 2007.

KEITEL, B. How to calculate the environmental costs? Case company cienfuegos. Visión de Futuro, v. 15, n. 2, p. 1-18, 2011. 
KHAN, M. W. J.; KHALIQUE, M. Strategic planning and reality of external environment of organizational in contemporary business environments. Business Management and Strategy, v. 5, n. 2, p. 165-182, 2014.

KOCSIS, T.; BEM, J. Has environmental management system always a cost reducing benefit for the adopting firm? In: INTERNATIONAL SCIENTIFIC CONFERENCE ON SUSTAINABLE DEVELOPMENT AND ECOLOGICAL FOOTPRINT, Hungary, 2012. Anais [...] Hungary, 2012.

Leite, a. f.; Fernandes, p. o.; Leite, j. m. Contingent factors that influence the use of management accounting practices in the Portuguese textile and clothing sector. The International Journal of Management Science and Information Technology, n. 19, p. $59-77,2015$

LUCAS, m.; rafferty, j. Cost analysis for pricing: explorating the gap between theory and practice. The British Accounting Review, v. 40, n. 2, p. 148-160, 2008

MARIE, A.; CHEFFI, W.; LOTUS, R. J.; RAO, A. Is standard costing relevant? Evidence from Dubai. Management Accounting Quarterly, v. 11, n. 2, p. 1-10, 2010

MARTINS, E. Contabilidade de custos. 10. ed. São Paulo: Atlas, 2010.

MUNIZ, L. S. Práticas de gestão estratégica de custos adotadas por empresas brasileiras. Dissertação (Mestrado em Ciências Contábeis). Universidade do Vale do Rio dos Sinos -Unisinos, São Leopoldo, 2010.

Ogungbade, o. i.; idode, p. e.; alade, m. e. An empirical investigation of the adoption status of the new management accounting techniques among Kenyan manufacturing companies. European Journal of Business, Economics and Accountancy, v. 4, n. 7, p. 68-78, 2016

OLIVEIRA, L. H. Exemplo de cálculo de ranking médio para Likert. Material da aula de Metodologia Científica e Técnicas de Pesquisa em Administração do curso de Mestrado em Administração e Desenvolvimento Organizacional. CNEC/FACECA. 2005. Disponível em: http://www.administradores.com.br/producao-academica/ranking-medio-paraescala-de-likert/28/download/ Acesso em: 01 set., 2018.

OYADOMARI, J. C.; MENDONÇA NETO, O. R.; CARDOSO, R. L.; LIMA, M. P. Fatores que influenciam a adoção de artefatos de controle gerencial nas empresas brasileiras: um estudo exploratório sob a ótica da teoria institucional. Revista de Contabilidade e Organizações (RCO), v. 2, n. 2, p. 55-70, 2008.

PEAVEY, D. E. It's time for a change. Management Accounting, n. 2, p. 31-35, Feb. 1998.

PERKINS, D. Incorporating the opportunity cost of setups into production-related decision. Management Accounting Quarterly, v. 6, n. 1, 2004.

PIVRU, C.; VASILESCU, L.; MEHEDINTU, A.; PIVRU, C. D. Implementation of strategic principles in cost management: control of cost variations through statistical studies. African Journal of Business Management, v. 6, n. 45, p. 11161-11170, 2012.

PONG, C.; MITCHELL, F. Full costing versus variable costing: does the choice still matter? An empirical exploration of UK manufacturing companies 1988-2002. The British Accounting Review, v. 38, n. 2, p. 131-148, 2006.

RAAJ, E. M. VERNOOJ, M. J. A.; TRIEST, S. The implementation of Costumer profitability analysis: a case study. Industrial Marketing Management, v. 32, n. 7, p. 573-583, 2003.

RASIA, K. A. Práticas de gestão estratégica de custos adotadas por empresas de segmentos do agronegócio. Dissertação (Mestrado em Ciências Contábeis), Universidade do Vale do Rio dos Sinos - Unisinos, São Leopoldo, 2011.

RECKZIEGEL, V.; SOUZA, M. A.; DIEHL, C. A. Práticas de gestão estratégica de custos adotadas por empresas brasileiras. Revista Brasileira de Gestão de Negócios (RBGN), v. 9, n. 23, p. 14-27, 2007.

ROSS, S. A.; WESTERFIELD, R. W.; JAFFE, J.; LAMB, R. Administração financeira. 10 ed. Porto Alegre: AMGH, 2015.

RUSSO, P. T.; GUERREIRO, R. Percepção sobre a sociomaterialidade das práticas de contabilidade gerencial. Revista de Administração de Empresas (RAE-FGV), v. 57, n. 6, p. 567-584, 2017 a.

RUSSO, P. T.; GUERREIRO, R. As práticas de contabilidade gerencial mais utilizadas por empresas que operam no Brasil. In: SEMINÁRIOS EM ADMINISTRAÇÃO (SEMEAD), 20. Anais [...]São Paulo, FEA/USP, 2017b.

SAKURAI, M. Gerenciamento integrado de custos. São Paulo, Atlas, 1997.

Schwarze, F; Wuellenweber, K.; Hackethal, A. Drivers and barriers to management accounting change. In: AAA 2008 MAS Meeting Paper. Anais... Disponível em: SSRN: https://ssrn.com/abstract=1003371 e http://dx.doi.org/10.2139/ssrn.1003371. Acesso em 05 mai. 2019.

SHANK, J. K. Strategic cost management: new wine or just new bottles? Journal of Management Accounting Research, v. 1, p. 46-65, 1989. 2000

SHINGO, S. Sistema de troca rápida de ferramenta: uma revolução nos sistemas produtivos. Porto Alegre: Bookman,

SILVA, E. L.; MENEZES, E. M. Metodologia da pesquisa e elaboração de dissertação. 4. ed. Florianópolis: UFSC, 2005.

SNELGROVE, T. Value pricing when you understand your customers: total cost ownership. Journal of Revenue and Pricing Management, v. 11, n. 1, p. 76-80, 2011.

Solomons, d. Divisional performance. Homewood, Irwin, 1965.

SOUZA, F. F.; GASPARETTO, V. G. Práticas de contabilidade gerencial adotadas por empresas inovadoras. In: CONGRESSO BRASILEIRO DE CUSTOS, 24. Florianópolis, ABC, 2017. Anais [...] Florianópolis: ABC, 2017. 
SOUZA, M. A.; FONTANA, F. B.; BOFF, C. D. S. Planejamento e controle de custos: um estudo sobre as práticas adotadas por empresas industriais de Caxias do Sul-RS. Contabilidade Vista \& Revista, v. 21, n. 2, p. 121-151, 2010.

SOUZA, M. A.; LISBOA, L. P.; ROCHA, W. Práticas de contabilidade gerencial adotadas por subsidiárias brasileiras de empresas multinacionais. Revista Contabilidade \& Finanças, v. 14, n. 32, p. 40-57, 2003.

SWENSON, D.; ANSARI, S.; BELL, J.; KIM, W. Best practices in target costing. Management Accounting Quarterly, v. 4, n. 2, p. 12-17, 2003.

TEIXEIRA, A. J. C.; GONZAGA, R. P.; SANTOS, A. V. S. M. S.; NOSSA, V. A utilização de ferramentas de contabilidade gerencial nas empresas do Estado do Espírito Santo. Brazilian Business Review, v. 8, n. 3, p. 108-127, 2011.

TEMTIME, Z. T. The moderating impacts of business planning and firm size on total quality management practices. The TQM Magazine, v. 15, n. 1, p. 52-60, 2003.

TURNEY, P. B. B.; ANDERSON, B. Accounting for continuous improvement. MIT Sloan Management Review, v. 30, n. 2, p. $37-47,1989$.

WARREN, C. S.; REEVE, J. M.; FESS, P. E. Contabilidade gerencial. 2. ed. São Paulo: Thomson Learning, 2008.

Weetman, P. Discovering the international in accounting and finance. British Accounting Review, v. 38, n. 4, p .351-370, 2006.

WILLIANSON O. The vertical integration of production: market failure considerations. The American Economic Review, v. 61, n. 2, p. 112-123. 1971

YAP, K. H. A.; LEE, T. H.; SAID, J.; YAP, S. T. Adoption, benefits and challenges of strategic management accounting practices: evidence from emerging Market. Asian Pacific Management Accounting Journal, v. 8, n. 2, p. 27-45, 2013.

ZHAO, X.; TANG, Q. Analysis and strategy of the Chinese logistic cost reduction. International Journal of Business and Management, v. 4, n. 4, p. 188-191, 2009.

ZENG, A. Z.; ROSSETTI, C. Developing a framework for evaluating the logistics costs in global sourcing process. International Journal of Physical Distribution \& Logistic Management, v. 33, n. 9, p. 785-803, 2003.

ZHENG, X. Management accounting practices in china: current key problems and solutions. Social Research, v. 29, n. 4, p. 9198, 2012. 